\title{
Estudo do agregado graúdo reciclado de concreto como agente de cura interna
}

\section{Study of aggregate graft recycled of concrete as an internal healing agent}

\author{
Beatriz Cordeiro de Souza ${ }^{1}$, Cássia Nayara dos Santos Paes ${ }^{2}$, Lucas da Silva Barboza ${ }^{3}$
}

\footnotetext{
${ }^{1}$ Graduanda em Engenharia Civil, UNASP -EC, CEP 13835-000, Engenheiro Coelho, SP, Brasil.

${ }^{2}$ Graduanda em Engenharia Civil, UNASP -EC, CEP 13835-000, Engenheiro Coelho, SP, Brasil.

${ }^{3}$ Professor Doutor do curso de Engenharia Civil, UNASP - EC, CEP 13835-000, Engenheiro Coelho, SP, Brasil e-mail: biacordeiro2013@hotmail.com, cassia_nay@hotmail.com, lucas.barboza@unasp.edu.br
}

\section{RESUMO}

O avanço nas construções civis e o aumento dos desperdícios nas obras tem induzido a busca por alternativas que substituam a matéria prima empregada. Visando a preservação do meio ambiente por meio da redução de extração da natureza, surgiu na construção a reciclagem dos materiais provenientes de perdas ou demolições. Entre as alternativas está o emprego do Agregado Reciclado de Concreto (ARC) em substituição ao agregado natural. Além disso, a pré-saturação do agregado no emprego do concreto pode exercer o papel de agente de cura interna. Esta pesquisa busca analisar o efeito do emprego de Agregados Graúdos Reciclados (AGRC) atuando como agente de cura interna no concreto. Por meio da substituição do agregado graúdo natural (AN) por AGRC definido por meio da compensação em massa, submetidos a dois tipos de cura (ao ar e submersa) e relação a/agl de 0,42 . Os resultados obtidos mostraram que a resistência dos concretos com ARC seco foram maiores. Na cura interna, o emprego de AGRC saturado não cumpriu a função de agente de cura interna.

Palavras-chave: Concreto, Agregado reciclado de concreto, Cura interna.

\section{ABSTRACT}

The advance in the civil constructions and the increase of the wastes in the works has induced the search for alternatives that substitute the used raw material. Aiming at the preservation of the environment through the reduction of nature extraction, the recycling of materials from losses or demolitions arose in the construction. Among the alternatives is the use of the Recycled Concrete Aggregate (RCA) to replace the natural aggregate. In addition, the pre-saturation of the aggregate in the concrete can act as an internal curing agent. This research seeks to analyze the effect of the use of Recycled Coarse Aggregates Concrete (RCAC) acting as an internal curing agent in concrete. By replacing the natural aggregate (NA) by AGRC defined by means of mass compensation, submitted to two types of curing (air and submerged) and a / agl ratio of 0.42 . The results showed that the resistance of the concrete with dry RCA was higher. In internal cure, the use of saturated RCAC did not fulfill the function of internal curing agent.

Keywords: Concrete, Concrete Recycled aggregate, Internal cure.

\section{INTRODUÇÃO}

Devido ao progressivo avanço da construção civil, a utilização dos recursos provenientes da natureza foram intensificados, de modo que a crescente geração de rejeitos sólidos, procedentes de construções e demolições vem afetando diretamente o meio natural, e o degradando desmedidamente.

A nível mundial, são produzidos aproximadamente 25 bilhões de toneladas de concreto pela indústria da construção civil por ano. Em proporção a este consumo, a emissão de $\mathrm{CO}_{2}$ pode atingir a marca de 1,25 a 3,25 bilhões de toneladas de gases. Assim, contribuindo de maneira efetiva para o efeito estufa e degradação da camada de ozônio [1,2]. 
$\mathrm{Na}$ tentativa de conter os danos ambientais ligados à indústria da construção civil, vários esforços de pesquisadores têm convergido para a utilização de agregados reciclados, com o intuito da redução do potencial de impacto ambiental, conservação de recursos naturais e prolongamento da vida útil de aterros [3-5]. Neste contexto, GUERRA et al. [6] e ZHANG et al. [7], afirmaram que a proposta por um desenvolvimento sustentável preconiza a elucidação de sistemas que agreguem resultados viáveis e que ofereçam uma construção sustentável e ecológica, buscando um desenvolvimento técnico em equilíbrio harmônico com o meio Ambiente.

Para atender a essas demandas crescentes dos canteiros de obras, a indústria da construção pode contribuir reciclando seus Resíduos de Construção e Demolição (RCD). Segundo ZHANG et al. [7] a utilização de agregados reciclados pode contribuir para melhorar a eficiência e sustentabilidade da construção civil, reduzindo o consumo de rejeitos depositados em aterros e conservação da matéria-prima.

Uma porção dos Resíduos de Construção Civil (RCC) são identificados como inativos devido sua composição ser um tanto disseminada, podendo também ser classificados como resíduo prejudicial devido a presença de certos materiais químicos [8]. Segundo a Resolução CONAMA nº 307/2012 do Conselho Nacional do Meio Ambiente [9], tais resíduos são oriundos de construções, demolições, reparos, escavações e demais atividades que geram o mais conhecido como entulhos de obra. Produzindo cerca de 0,4 a 0,7 t/hab.ano o RCC corresponde a $2 / 3$ do total dos resíduos sólidos gerados nos municípios, ou seja, duas vezes maior que os resíduos domiciliares [10].

Devido ao grande volume de resíduos que são descartados na construção civil, e do alto consumo de agregados naturais utilizados nas construções, uma possibilidade é a substituição do agregado natural pelos resíduos remodelado em agregados [11].

Segundo o SindusCon [10], cerca de $70 \%$ dos resíduos gerados na construção civil são oriundos de pequenos geradores tais como pequenas obras, reformas e demolições, e os 30\% restantes são provenientes de novas construções. A mesma fonte apontou que no estado de São Paulo cerca de 40 municípios possuem um programa de gerenciamento e legislação específica de RCC.

Pesquisadores como CANTERO et al. [12], Gonzalez-Corominas e Etxeberria [13] e SINGH e SCANLON [14], ao analisarem concretos com agregados reciclados em sua composição de modo parcial ou total ao agregado natural obtiveram resultados não satisfatórios no concreto em estado fresco. Isso ocorre devido à alta porosidade do agregado reciclado, e consequentemente, absorvem a água contida na mistura afetando a trabalhabilidade do concreto, sendo necessário o aumento de água na mistura, resultando no aumento da relação a/c, causando uma redução de $25 \%$ da resistência do concreto com agregado natural, modificado para Agregado Reciclado de Concreto (ARC) [15]. Para compensar a perda de trabalhabilidade, se faz necessário a utilização de superplastificante, contribuindo para a redução da relação a/c, favorecendo para manter ou aumentar a resistência à compressão no que concerne ao concreto com agregado natural [16].

$\mathrm{Na}$ fabricação com ARC, deve-se considerar a retração do concreto, causada diretamente pelo extravio de água da pasta de cimento [17]. Este efeito pode ser reduzido com o processo de cura interna, que é a saturação do ARC devido sua maior porosidade, absorvendo água, considerada água livre que auxiliará na hidratação dos fragmentos de cimento [18].

Segundo NEVILLE e BROOKS [19], a resistência e durabilidade do concreto nas obras são bastante afetadas se não forem controlados com a cura correta. A cura do concreto é um procedimento que proporciona a hidratação do mesmo, com o propósito ao desenvolvimento da resistência do concreto.

Os métodos de cura usuais na obra consistem em umedecer o concreto poucas vezes ao dia, e por tempo insuficiente, o que acarreta a redução da durabilidade e resistência do concreto [20].

A água de amassamento é parte fundamental no processo de pega e endurecimento, no qual sua perda pode ocasionar vazios e, consequentemente, a retração por secagem. Portanto, uma mistura dosada corretamente e submetida a cura úmida, se tornará um material com baixa permeabilidade, boa resistência à carbonatação, baixa absorção de água e, consequentemente, boa resistência mecânica e durabilidade [21].

CARRIJO [22] comentou que concretos produzidos com agregado reciclado possuem uma grande influência em relação à resistência à compressão, isso ocorre devido a menor resistência mecânica e a presença de fases mais porosas nas partículas do agregado, como por exemplo, produtos cerâmicos e argamassas encontradas na composição do agregado reciclado de concreto.

Concretos com agregados reciclados são introduzidos em argamassas de cimento novo, contudo esse tipo de agregado possui uma camada de argamassa antiga, com menor resistência, que não foi totalmente removida nos processos de reciclagem. Na mistura atualizada deve ser levada em consideração uma proporção dessa camada já existente, para equilibrar a ligação de menor resistência entre os agregados e a matriz, de 
forma que a resistência do concreto novo não seja afetada pela camada de argamassa dos agregados reciclados, tendo um alcance de resistência eficaz comparada a concretos convencionais [23].

Todavia é preciso ter cuidado com a substituição do agregado convencional pelo agregado reciclado. É de grande importância ter o conhecimento do material, para controle de suas propriedades mecânicas e duráveis, bem como obtenção de níveis de resistência comparados com agregados convencionais [24].

Utilizar agregados reciclados, além de incorporar novos produtos ao mercado, também cria benefícios extras, muitas vezes viabilizando projetos de níveis sociais, devido ao custo ser menor que os concretos convencionais [25].

Neste cenário, a pesquisa apresenta uma análise da incorporação de agregados reciclados em misturas de concretos, analisando a influência desta substituição na resistência à compressão e a viabilidade da utilização do RCD como agente de cura interna em diferentes idades e diferentes tipos de cura. Ressalta-se que o assunto em questão se torna relevante, uma vez que é possível uma contribuição significativa da redução dos custos provenientes da remoção de despejo, contribuindo para a implantação de resíduos reciclados no mercado e possibilitando a diminuição de impactos ambientais procedentes da incorreta dispersão dos mesmos.

\subsection{Agregados reciclados como agente de cura interna}

O processo de cura da estrutura de concreto tem grande importância para que as características e especificações do projeto sejam atendidas. Este processo deve ser realizado imediatamente após a disposição e adensamento do concreto, e assim que externar os primeiros indícios de endurecimento em sua superfície [19]. O tempo mínimo deve durar de 7 a 10 dias em média [26].

Segundo HELENE e LEVY [20], os procedimentos comuns de cura utilizados em obras não são eficientes para o auxílio do aumento da resistência do concreto. $\mathrm{O}$ ato de umedecer o concreto superficialmente não propicia quantidade de água considerável às reações de pega e endurecimento. Segundo os mesmos autores, os intervalos no processo de cura geram perda de água do concreto, formando vazios e aumento da porosidade, tornando-o vulnerável aos agentes externos, implicando na resistência e durabilidade. Devido a isso, a utilização de um fluxo de água constante possui maior eficiência que um fluxo ocasional [19].

Para NEVILLE e BROOKS [19], um ponto essencial que deve ser dado importância ao determinar os procedimentos de cura do concreto, é o fator água-cimento, que estabelece uma conexão entre o nível de cuidado que se deve ter com a estrutura, ou seja, quanto menor a relação água-cimento, menores os cuidados exigidos.

A cura do concreto é dividida em cura externa, que é a tradicional utilizada nas obras, e em cura interna, que consiste na utilização de material considerado "acumulador de água" inseridos na mistura. Esse material tem a função de armazenar considerável quantidade de água e liberá-la no processo de hidratação do cimento. Estas propriedades são identificadas em agregados reciclados, agregados leves e polímeros superabsorventes [27].

Com o intuito de restituir a absorção de água do ARC, são utilizados métodos de pré-saturação ou prémolhagem. Este método é sugerido devido aos agregados possuírem capacidade de absorver água destinada a hidratação do cimento e trabalhabilidade do concreto, gerando a necessidade de uma compensação dessa água absorvida pelo material [28].

A absorção de água dos agregados reciclados tem influência direta nas propriedades do concreto. Agregados reciclados quando empregados no estado seco absorvem água considerável da mistura, influenciando de forma negativa na trabalhabilidade. Devido a isso é recomendado a pré-molhagem do agregado reciclado previamente a mistura [29].

BUTLER [29] e CABRAL et al., [30] afirmaram após estudos envolvendo agregado graúdo reciclado, no estado saturado de superfície seca, que estes podem exercer a função de agente de cura interna, pois a eventual presença da água acumulada no interior do grão do ARC ocasiona melhorias no processo de cura interna.

A água absorvida pelos agregados reciclados na pré-molhagem, torna-se livre no interior da pasta, hidratando as partículas de cimentos ainda não hidratadas, contribuindo no processo de cura do concreto. Além disto, a água presente no agregado propicia o desenvolvimento de boa zona transição entre pasta e agregado [31].

\section{MATERIAIS E MÉTODOS}

Os ensaios de resistência à compressão foram elaborados seguindo a ABNT NBR 5739 (2018) [32], no laboratório do Núcleo de Tecnologia de Engenharia e Arquitetura (NUTEA) do Centro Universitário adventista 
de São Paulo - UNASP. Os materiais utilizados estão discretezados a seguir.

\subsection{Materiais utilizados nas dosagens}

Para esta pesquisa foi utilizado agregado reciclado cinza, oriundo de concreto encontrado atualmente no mercado na cidade de Guarulhos - SP, já os agregados graúdos e miúdos naturais e cimento, são facilmente encontrados comercialmente, na cidade de Engenheiro Coelho - SP, local do desenvolvimento da pesquisa.

\subsubsection{Cimento}

Foi empregado cimento do tipo CPII Z 32 (adição de pozolana), com massa específica de $3,15 \mathrm{~g} / \mathrm{cm}^{3}$ especificado pelo fabricante e produzido pela empresa Votorantim. A escolha para este cimento foi devido a sua disponibilidade e utilização na construção civil, na região do desenvolvimento da pesquisa.

\subsubsection{Agregado graúdo natural}

Foi empregado um agregado graúdo natural sendo de origem de rocha basáltica fragmentada e britada com dimensão máxima característica 19,5 mm, e módulo de finura igual a 2,64, conforme a ABNT NBR NM 248 (2003) [33]. Por meio dos ensaios de caracterização obteve-se massa específica do agregado seco de 2,93 $\mathrm{g} / \mathrm{cm}^{3}$ conforme a ABNT NBR NM 53 (2009) [34], massa unitária no estado solto de 1,51 g/ $/ \mathrm{cm}^{3}$, índice de vazios de 48,46\% conforme ABNT NBR NM 45 (2006) [35], e absorção de água de 1,14\%.

\subsubsection{Agregado miúdo}

Foi empregado como agregado miúdo uma areia grossa do tipo quartzosa com dimensão máxima característica de 4,8 mm, módulo de finura 2,46, conforme ABNT NBR NM 248 (2003) [33]. Por meio dos ensaios de caracterização obteve-se massa específica do agregado seco de $2,62 \mathrm{~g} / \mathrm{cm}^{3}$ conforme ABNT NBR NM 52 (2009) [36], massa unitária em estado solto $1,68 \mathrm{~g} / \mathrm{cm}^{3}$ e índice de vazios de $35,88 \%$ conforme ABNT NBR NM 45 (2006) [35].

\subsubsection{Agregado graúdo reciclado de concreto}

Foi utilizado agregado reciclado de concreto oriundo de pré-moldados com dimensão máxima característica de 19,5 mm, e módulo de finura igual a 2,07 conforme a ABNT NBR NM 248 (2003) [33]. Por meio dos ensaios de caracterização obteve-se massa específica do agregado seco de $2,57 \mathrm{~g} / \mathrm{cm}^{3}$ conforme a ABNT NBR NM 53 (2009) [34], massa unitária no estado solto de $1,27 \mathrm{~g} / \mathrm{cm}^{3}$, índice de vazios de 50,58\% conforme ABNT NBR NM 45 (2006) [35], e absorção de água de 6,16\%.

\subsubsection{Dosagens dos concretos}

As dosagens foram realizadas a fim de manter a relação água/cimento de 0,42 e um consumo de cimento de $450 \mathrm{~kg} / \mathrm{m}^{3}$ de acordo com Jordani [37]. Para se substituir o agregado natural por ARC, se fez necessário a compensação em massa (Equação 1) devido as diferentes massas específicas dos materiais, mantendo assim a constância do volume da pasta de aglomerante.

$$
M_{A R C}=\frac{M_{A N}}{\gamma_{A N}} X \gamma_{A R C}
$$

Sendo:

$\mathrm{M}_{\mathrm{ARC}}=$ Massa do agregado reciclado;

$\mathrm{M}_{\mathrm{AN}}=$ Massa do agregado natural;

$\gamma_{\mathrm{AN}}=$ Massa específica do agregado natural;

$\gamma_{\mathrm{AN}}=$ Massa específica do agregado reciclado;

A relação de dosagens estudadas e seus respectivos consumos de cimento para cada uma delas estão apresentados na Tabela 1. Cada dosagem foi produzida com apenas uma mistura. A determinação da quantidade de ARC foi realizada de acordo com JORDANI [37]. 
Tabela 1: Consumo de materiais para os traços estudados, para $1 \mathrm{~m}^{3}$ de concreto.

\begin{tabular}{|c|c|c|c|c|c|c|}
\hline AGREGADO & A/AGL & $C\left(K G / M^{3}\right)$ & AREIA $\left(M^{3}\right)$ & BRITA $\left(M^{3}\right)$ & $\operatorname{ARC}\left(M^{3}\right)$ & ÁGUA \\
\hline $\mathrm{CR}$ & 0,42 & 450 & 799 & 1065 & 0 & 189 \\
\hline CAR-S & 0,42 & 450 & 799 & 534 & 442 & 189 \\
\hline CAR-U & 0,42 & 450 & 799 & 534 & 442 & 189 \\
\hline
\end{tabular}

CR - Concreto de referência com agregado natural; CAR-S - Concreto com agregado graúdo reciclado seco; CAR-U Concreto com agregado graúdo reciclado pré-saturado.

A dosagem CR, trata-se do concreto produzido apenas com o agregado graúdo natural basáltico, sendo o concreto de referência. A segunda dosagem, CAR-S, trata-se do concreto produzido com substituição parcial de 50\% do agregado natural pelo agregado reciclado, no qual o RCD encontra-se seco, sem pré-saturação. E por fim, a dosagem CAR-U é referente ao concreto produzido com substituição parcial de $50 \%$ do agregado natural pelo agregado reciclado, condicionado a pré-saturação antes da aplicação à mistura. Após a moldagem e endurecimento das amostras, para as distintas dosagens, as mesmas foram submetidas a dois tipos de curas, cura ao ar e cura submersa, respectivamente.

Por fim, foram realizadas 6 dosagens distintas. No qual, contemplam dois tipos de curas e três condições dos agregados graúdos.

\subsubsection{Cura do concreto}

Os concretos estudados foram submetidos a dois tipos de cura: cura submersa e cura ao ar. A cura submersa consiste na imersão dos corpos de prova em tanque de água como proposto pela ABNT NBR NM 5738 (2015) [38], até o dia da ruptura. Contudo, BAUER [37] afirmou que, a cura submersa é o método mais eficaz, porém, é limitada e sem praticidade para execução em obras.

Já o processo de cura ao ar é totalmente influenciado pelo local onde está exposta. Situação, no qual se aproxima da realidade decorrente do canteiro de obra [39]. A cura ao ar é basicamente expor o concreto as intempéries do ambiente sem nenhum controle de temperatura e umidade. No Brasil, devido às altas temperaturas anuais simultâneas, a umidade do ar atua de forma negativa na cura do concreto [40].

\section{RESULTADOS E DISCUSSÕES}

Nesta seção está apresentado e analisado todo o programa experimental, sobre a utilização do agregado reciclado de concreto como agente de cura interna do concreto e resistência aos dois tipos de cura analisados.

\subsection{Resistência à compressão}

Para cada traço especificado, foram produzidos 3 corpos de prova para as idades de 3,7 e 28 dias submetidos a cura submersa e cura seca.

Os resultados da resistência à compressão para os dois tipos de cura e para as diferentes idades estudadas são apresentados na Tabela 2 .

Tabela 2: Resultados de Resistência à compressão, nas idades de 3, 7 e 28 dias.

\begin{tabular}{c|c|c|c|c|c|c}
\hline \multicolumn{7}{c}{ ENSAIO DE RESISTÊNCIA À COMPRESSÃO - 3 DIAS } \\
\hline AMOSTRAS & CR-SUB & CR-AR & CAR-S-SUB & CAR-S-AR & CAR-U-SUB & CAR-U-AR \\
\hline CP1 & - & 23,60 & 24,31 & 21,18 & 21,47 & 18,09 \\
\hline CP2 & 26,70 & 19,89 & 26,66 & 21,27 & 21,16 & 18,31 \\
\hline CP3 & 22,56 & 22,37 & 29,18 & 23,34 & 21,69 & 19,02 \\
\hline$f_{\text {cm }}(\mathrm{MPa})$ & 24,63 & 21,95 & 26,72 & 21,93 & 21,44 & 18,47 \\
\hline Desvio Padrão (MPa) & 1,84 & 0,73 & 0,96 & 0,43 & 0,10 & 0,18 \\
\hline Coef. De Variação & $7,45 \%$ & $3,33 \%$ & $3,59 \%$ & $1,94 \%$ & $0,49 \%$ & $0,99 \%$ \\
\hline \multicolumn{7}{c}{ ENSAIO DE RESISTÊNCIA À COMPRESSÃO - 7 DIAS } \\
\hline
\end{tabular}




\begin{tabular}{c|c|c|c|c|c|c}
\hline AMOSTRAS & CR-SUB & CR-AR & CAR-S-SUB & CAR-S-AR & CAR-U-SUB & CAR-U-AR \\
\hline CP1 & 24,68 & 25,17 & 29,21 & 27,39 & 22,13 & 20,80 \\
\hline CP2 & 31,13 & 23,39 & 25,36 & 25,85 & 24,62 & 20,90 \\
\hline CP3 & 30,23 & 28,18 & 21,77 & 29,24 & 22,25 & 21,41 \\
\hline$f_{\text {cm }}(\mathrm{MPa})$ & 28,68 & 25,58 & 25,45 & 27,49 & 23,00 & 21,04 \\
\hline Desvio Padrão $(\mathrm{MPa})$ & 1,27 & 0,94 & 1,46 & 0,67 & 0,49 & 0,12 \\
\hline Coef. De Variação & $4,43 \%$ & $3,69 \%$ & $5,76 \%$ & $2,43 \%$ & $2,13 \%$ & $0,57 \%$ \\
\hline
\end{tabular}

ENSAIO DE RESISTÊNCIA À COMPRESSÃO - 28 DIAS

\begin{tabular}{c|c|c|c|c|c|c}
\hline AMOSTRAS & CR-SUB & CR-AR & CAR-S-SUB & CAR-S-AR & CAR-U-SUB & CAR-U-AR \\
\hline CP1 & - & - & 34,42 & 30,16 & 28,75 & 23,68 \\
\hline CP2 & 29,27 & 29,41 & 37,27 & 34,02 & 29,02 & 25,88 \\
\hline CP3 & 24,55 & 31,68 & 29,64 & 30,22 & 27,30 & 25,62 \\
\hline$f_{\text {cm }}(\mathrm{MPa})$ & 26,91 & 30,55 & 33,78 & 31,47 & 28,36 & 25,06 \\
\hline Desvio Padrão $(\mathrm{MPa})$ & 2,09 & 1,01 & 1,50 & 0,76 & 0,34 & 0,43 \\
\hline Coef. De Variação & $7,78 \%$ & $3,30 \%$ & $4,45 \%$ & $2,42 \%$ & $1,19 \%$ & $1,72 \%$ \\
\hline
\end{tabular}

CR-SUB - Concreto com agregado natural com cura submersa; CR-AR - Concreto com agregado natural com cura ao ar; CAR-S-SUB - Concreto com agregado reciclado seco com cura submersa; CAR-S-AR - Concreto com agregado reciclado seco com cura ao ar; CAR-U-SUB - Concreto com agregado reciclado úmido com cura submersa; CAR-U-AR - Concreto com agregado reciclado úmido com cura ao ar.

As médias das resistências à compressão apresentadas na Tabela 2 seguem um crescimento linear e constante conforme acréscimo de idades. Os coeficientes de variação apresentaram níveis adequados conforme análise proposta pela ABNT NBR NM 5739 (2018) [32], exceto os coeficientes encontrados para o CR-SUB nas idades de 3 e 28 dias, respectivamente, isto pode ter ocorrido devido ao adensamento ter sido feito em corpos de provas moldados com um tempo superior aos demais, prejudicando a trabalhabilidade do material. Um fator que também possa ter acarretado esses valores pode ser devido ao tempo de vibração, que ocasiona a segregação do material se não realizado no instante correto.

A Figura 1 apresenta as médias de resistência à compressão de cada dosagem estudada relacionadas com o tipo de cura que foram submetidos, e as diferentes idades que foram ensaiadas.

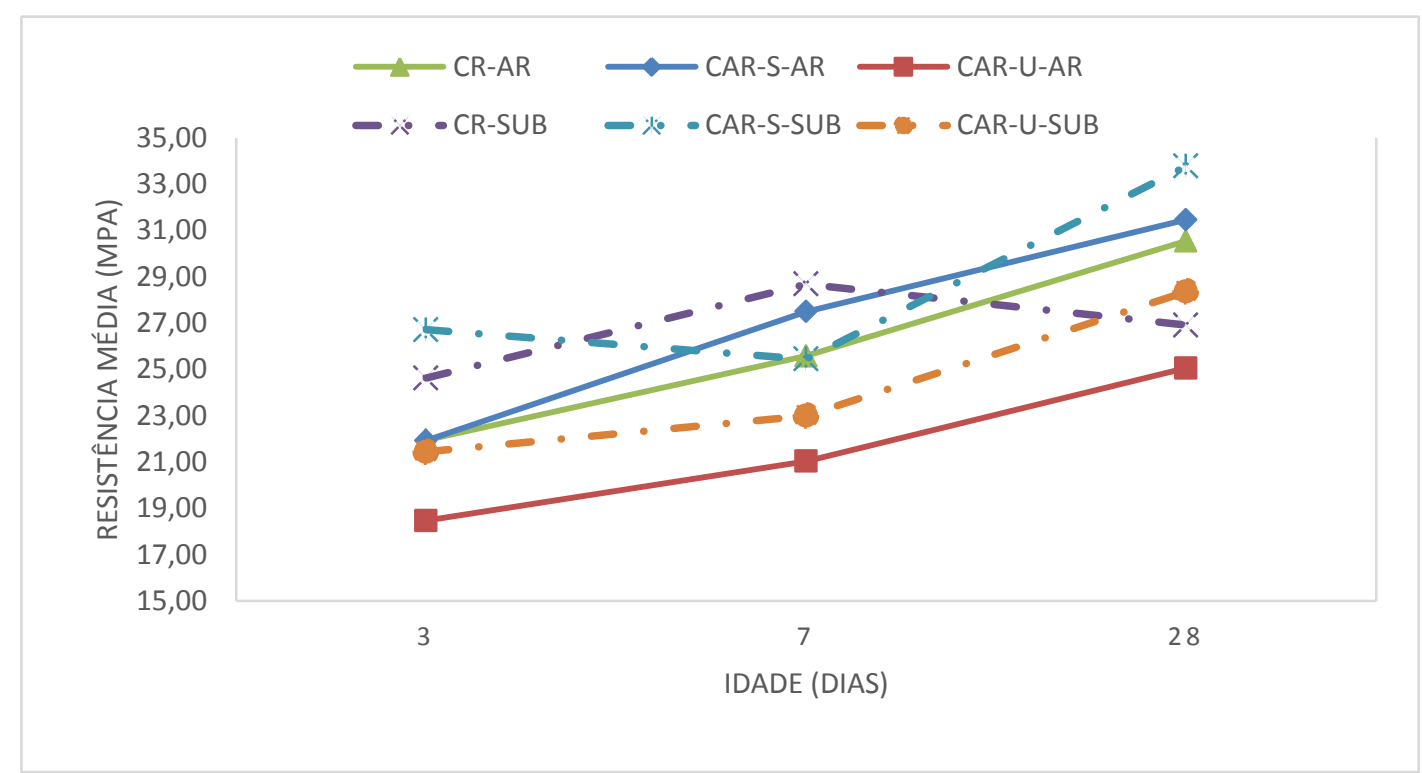

Figura 1: Resultados das médias de resistência à compressão para cura submersa e cura seca. 
Pode-se observar na Figura 1, com relação à cura submersa, que o concreto composto por agregado reciclado seco apresentou resistência superior aos demais, com exceção da ruptura aos 7 dias, no qual percebe-se uma redução da resistência e sua retomada aos 28 dias. Isso pode ter ocorrido devido à seleção de um lote de amostras que sofreram algum tipo de danificação durante o processo de moldagem, podendo ser justificado uma vez que o comportamento de 3 e 28 dias apresentaram-se superior, mantendo o comportamento. Esse aumento de resistência foi verificado por BUTTLER [29], ao analisar concreto com agregado reciclado seco ser submetido a mistura diretamente em contato com a água de amassamento, gerando um processo de cura interna.

Já com relação à cura seca, ficou evidente a constância no acréscimo da resistência à compressão. O concreto com agregado reciclado seco apresentou resistência superior aos demais em todas as idades, podendo ser fundamentado pela maior porosidade presente no material se comparado com o agregado natural, devido o processo de cura úmida interna, presente no agregado reciclado, que absorve a água de amassamento gerando uma reserva de água que posteriormente servirá para a hidratação das partículas, reduzindo a relação $\mathrm{a} / \mathrm{c}$, aumentando significativamente a resistência conforme as idades aumentam.

O concreto composto por agregado reciclado saturado propiciou para a liberação de água na pasta de concreto alterando a relação água cimento, e este pode ser uma das causas que levou o concreto CAR-U a apresentar a menor resistência comparado com o concreto CR e o concreto CAR-S. Em sua pesquisa Paulon [41] explicou quanto maior for à proporção de partículas lamelares e alongadas dos agregados haverá uma tendência maior de acúmulo de água em películas próximas as partículas, podendo diminuir a resistência da pasta de cimento na região de interface. $\mathrm{O}$ aumento da relação a/c no concreto provoca a diminuição de resistência, e devido a não homogeneidade dos agregados devido a possibilidade de haver agregado natural em sua composição, não absorve a água o suficiente, e os que absorvem, liberam parte no processo de amassamento, podendo ser um dos fatores que ocasionou a perda de resistência [41].

Ao analisar a resistência nos ambientes de cura obteve-se melhores resultados do agente de cura interna na cura submersa, devido a uma constante hidratação das partículas e dos finos presentes nos agregados proporcionando um melhor desempenho da resistência final. No ambiente seco que é onde se esperava melhor atuação, não foi atendido, considerando que esse tipo de cura se expõe a todas as intempéries climáticas, tendo umidade do ar como fator prejudicial considerando a inconstância de temperatura durante um mesmo dia, podendo ser um dos motivos que levou a obter melhor resultados no ambiente submerso.

A análise dos agregados isolados é apresentada na Figura 2, correlacionando agregados, curas e idades do concreto.

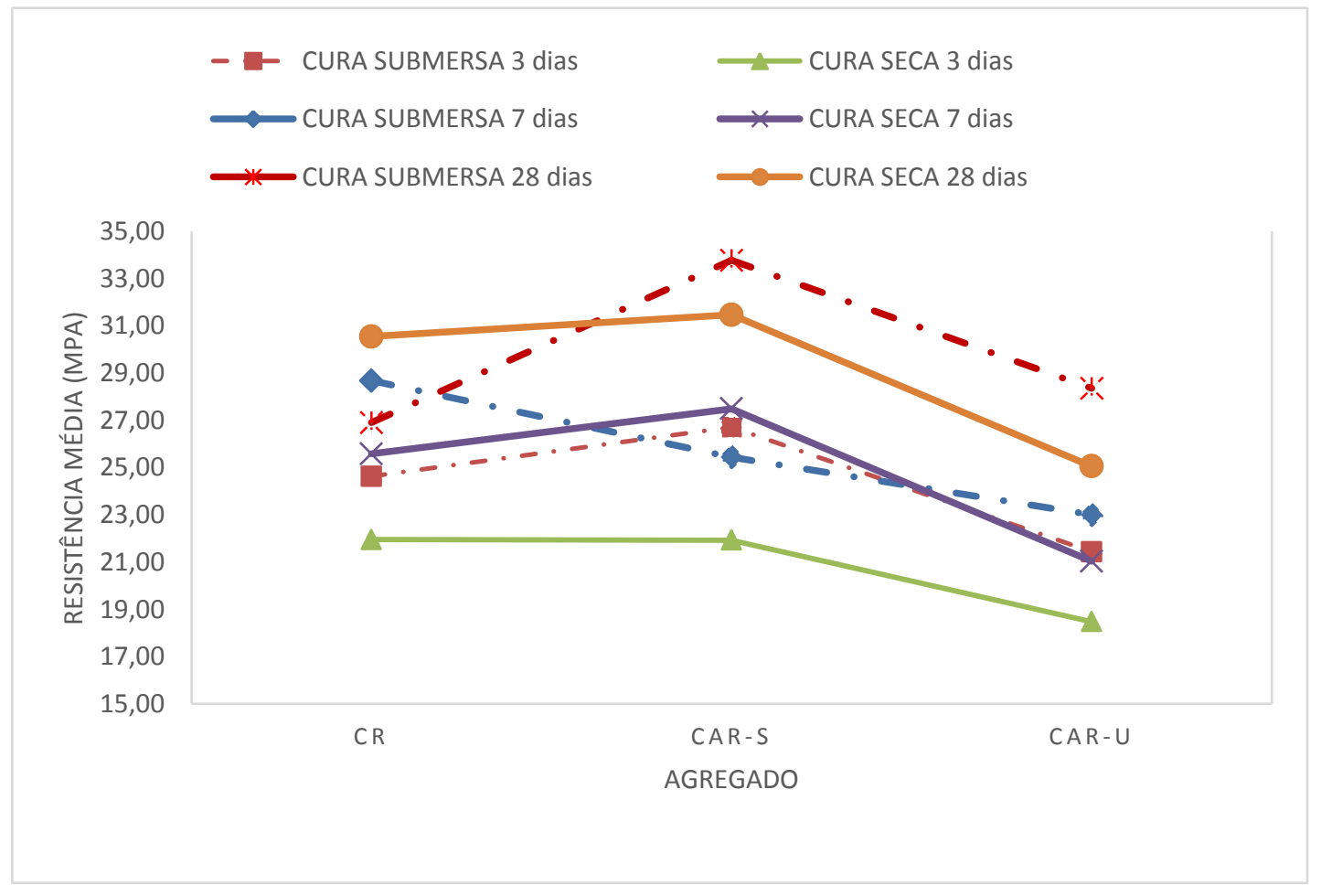

Figura 2: Efeitos dos agregados na resistência à compressão média nas idades de 3, 7 e 28 dias. 
Ao analisar os concretos isolados constituídos por agregado reciclado seco comparados com o saturado, percebe-se que para todos os casos obteve-se uma maior resistência no concreto CR-AR, com exceção da cura aos 7 dias como já mencionado anteriormente. As resistências encontradas para os dois agregados se mantiveram próximas, assumindo-se como provável o fato de que a absorção de água de amassamento contida no agregado reciclado seco causou a redução da relação a/agl efetiva da matriz promovendo um maior ganho de resistência se comparada com o agregado reciclado saturado.

BUTTLER [29] em sua pesquisa analisou que o concreto com agregado reciclado seco em contato com a água de amassamento, percebeu este aumento de resistência devido à absorção da água pelo agregado, gerando um reservatório. BUTTLER [42], em pesquisas realizadas, justifica este comportamento devido a possibilidade de haver grãos de cimento ainda não hidratadas no agregado, e sendo hidratadas no procedimento de mistura. Outro ponto citado pelo mesmo autor é a migração de água presente no agregado para a pasta de cimento, promovendo uma melhora nas propriedades da zona de transição pelo efeito de "cura interna". Isso também ocorre se comparadas as resistências do agregado reciclado seco com o agregado natural, pois se percebe que a uma provável melhoria na zona de transição do agregado reciclado por absorção de água de amassamento, tendo um melhor desempenho na interface da relação pasta/agregado.

LEITE [43] em sua pesquisa também constatou que o agregado reciclado apresenta uma textura de maior rugosidade, proporcionando uma melhoria na zona de transição, tendo em vista que a porosidade do agregado atrai a migração de íons deixando esta região mais densa que consequentemente, auxilia no intertravamento mecânico entre matriz e agregado.

O aumento de resistência com o concreto CAR-S em relação ao concreto CAR-U resultou em melhoria na zona de transição por meio da penetração da mistura de hidratação do cimento nos agregados porosos, atuando como entrelaçamento mecânico. Essa verificação é coerente com os apresentados por Vargas et al. [44]. Isto ocorre devido à existência de argamassa de cimento vinculada ao agregado reciclado, promovendo uma melhora na interface agregado e pasta, além deste possuir superfície rugosa [45, 46].

\section{CONCLUSÃO}

Baseado nos resultados deste estudo percebe-se que para todos os traços analisados, os concretos produzidos com o concreto CAR-S obtiveram maior resistência, comparados com agregado natural e concreto CAR-U. $\mathrm{Na}$ análise dos ambientes de cura, os concretos com concreto CAR-U obtiveram melhores resultados submetidos à cura úmida. $\mathrm{O}$ concreto $\mathrm{CAR}-\mathrm{S}$ se manteve com resistência maior que os outros agregados estudados tendo como fator principal a sua porosidade e absorção de água que demandou um acréscimo constante de resistência fazendo com que a relação pasta/agregado tivesse um melhor desempenho.

O presente trabalho apresentou a concepção de ensaios para verificação de conceitos de cura interna em ambientes secos, onde esse tipo de cura seria mais solicitado, contudo os resultados encontrados evidenciaram que a cura interna não se mostrou eficiente para tal situação visto que, a mesma não auxiliou para um ganho evidente de resistência, inutilizando o uso da cura interna para tal função.

A atuação de agente de cura interna que era para ser verificado na cura seca e onde se necessita da cura interna não foi eficaz. Portanto, o agregado reciclado de concreto não se comportou como agente de cura interna na cura seca, como era esperado.

\section{BIBLIOGRAFIA}

[1] OBLA, K.H., What is green concrete? Indian Concr. J. 24, p. 26 e 28, 2009.

[2] SIDDIQUE, R., SINGH, G., SINGH, M., Recycle option for metallurgical by-product (Spent Foundry Sand) in green concrete for sustainable construction. J. Clean. Prod. 172, p. 1111e 1120, 2018.

[3] GUO, Z., TU, A., CHEN, C., LEHMAN, D.E. Mechanical properties, durability, and life-cycle assessment of concrete building blocks incorporating recycled concrete aggregates. J. Clean. Prod. 199, p. 136 e 149,2018

[4] HUDA, S.B., SHAHRIA ALAM, M., Mechanical and freeze-thaw durability properties of recycled aggregate concrete made with recycled coarse aggregate. J. Mater. Civ. Eng. v. 27, n. 10, 04015003, 2015.

[5] KARTAM, N., AL-MUTAIRI, N., AL-GHUSAIN, I., AL-HUMOUD, J., Environmental management of construction and demolition waste in Kuwait. Waste Manag. v. 24, n.10, p. 1049 e 1059, 2004.

[6] GUERRA, J.S.; GUSMÃO, A. D.; SUKAR, S. F.; SIQUEIRA, M. S.; Avaliação da Gestão de Resíduos de Construção de Edifícios na Cidade do Recife. In: XII Encontro Nacional de Tecnologia do Ambiente Construído - ENTAC. Fortaleza, 2008. 
[7] ZHANG, L. W, SOJOBI, A. O., KODUR, V. K. R., el al., Effective utilization and recycling of mixed recycled aggaegates for a greener environment. Journal of Cleaner Production. v.23, n.11, p. 117600, 2019.

[8] CÓRDOBA, R. E. Estudo do sistema de gerenciamento integrado de resíduos de construção e demolição do município de São Carlos - SP, Dissertação de M. Sc., Escola de Engenharia de São Carlos, Universidade de São Paulo, USP, São Carlos, SP, 2010.

[9] BRASIL. Ministério do Meio Ambiente. Conselho Nacional do Meio Ambiente (CONAMA). Resolução CONAMA n 307 , de 05 de julho de 2002. Estabelece diretrizes, critérios e procedimentos para a gestão dos resíduos da construção civil. Diário Oficial da União, Brasília - DF, n. 136, 17 jul. 2002, p.95-96. Disponível em: 〈http://www.mma.gov.br/port/conama/legiabre.cfm?codlegi=307>.Acessado em: 4 março de 2019.

[10] SINDUSCON. Resíduos da construção civil e o estado de São Paulo. Sindicato da indústria da construção civil do estado de São Paulo 2012, Comitê de meio ambiente do SindusCon SP.

[11] PANDOVAN, R. G. Influência da pré-molhagem nas propriedades de concretos produzidos com agregados reciclados de concreto. Dissertação (mestrado em Engenharia Civil) - Universidade do Vale do Rio dos Sinos, São Leopoldo, 2013.

[12] CANTERO, B., DEL BOSQUE, I.S., MATÍAS, A., MEDINA, C.,Statistically significant effects of mixed recycled aggregate on the physical-mechanical properties of structural concretes. Constr. Build. Mater. 185 , p. 93 e 101, 2018.

[13] GONZALEZ-COROMINAS, A., ETXEBERRIA, M., Properties of high performance concrete made with recycled fine ceramic and coarse mixed aggregates. Constr. Build. Mater. N. 68, p. 618 e 626, 2014.

[14] SINGH, P., SCANLON, A., Concrete in Residential Construction. Pennsylvania Housing Research Centre, USA, 2013.

[15] HISHAM, Q.; IQBAL, M.; HSAN, T. Use of recycled concrete rubbles as coarse aggregate in concrete. The Hashemite University Zarqa, JORDAN. 2012.

[16] NOGUEIRA, J. R. S. Avaliação da influência do método de mistura nas propriedades de concretos produzidos com agregado graúdo reciclado de concreto. São Leopoldo, 2015. 120f. Dissertação (Mestrado em Engenharia Civil) - Programa de Pós-graduação em Engenharia Civil, Unisinos, São Leopoldo, 2015.

[17] RECENA, F.A.P. Retração do concreto. EDIPUCRS; Edição:1, 2014.

[18] KOVLER, K.; JENSEN, O. M. Novel techniques for concrete curing. Concrete International, v. 27, n.: 9, pp. 39- 42, Sep. 2005.

[19] NEVILLE, A.M.; BROOKS,J.J. Tecnologia do concreto. 2. ed. Porto Alegre: Brookman, 2013. 448p.

[20] HELENE, P.; LEVY, S. Boletim Técnico - Cura do Concreto. Mérida, México: ALCONPAT, 2013. 12 p. Disponível em: Acesso em: 13 mar. 2019.

[21] FERNANDES, J.; BITTENCOURT, T.N., HELENE, P. A Review of the Application of Concrete to Offshore Structures. Chapter 25. In: Fifth ACI/CANMET International Conference on High-Performance Concrete Structures and Materials. ACI SP-253. Farmington Hills, Michigan: American Concrete Institute, ISBN 978-0-87031-277-9, p. 393-408, 2008.

[22] CARRIJO, P. M. Análise da influência da massa específica de agregados graúdos provenientes de resíduos de construção e demolição no desempenho mecânico do concreto. São Paulo, Dissertação (Mestrado) Escola Politécnica, Universidade de São Paulo. p. 129, 2005.

[23] XIAO, J.; XIE, H. e YANG, Z. Shear transfer across a crack in recycled aggregate concrete. Cement and Concrete Research. February, pp. 700-709, 2012

[24] AZÚA, G., GONZALEZ, M., ARROYO, P., el al.,Recycled coarse aggregates from precast plant and building demolitions: environmental and economic modeling through stochastic simulations. J. Clean. Prod. 210, 1425 e 1434, 2019.

[25] ALVES, A., VIEIRA, T., de BRITO, J., el al.,Mechanical properties of structural concrete with fine recycled ceramic aggregates. Constr. Build. Mater. 64, 103 e 113, 2014.

[26] BAUER, L. A. F. Materiais da construção. 5. ed. revisada. Rio de Janeiro: LTC, 2011.

[27] REPETTE, W.L. Concreto Autoadensável. In: Geraldo Cechella Isaia. (Org.). Concreto Ciência e Tecnologia. 1ed. São Paulo: Instituto Brasileiro do Concreto, 2011.

[28] ETXEBERRIA, M.; VÁZQUEZ, E.; MARÍ, A.; el al.,Influence of amount of recycled coarse aggregates and production processo $\mathrm{n}$ properties of recycled aggregate concrete. Cement and Concrete Research, v.37, p.735-742, 2007. 
[29] BUTTLER, A.M. Concreto com Agregados Graúdos Reciclados de Concreto - Influência da Idade de Reciclagem nas Propriedades dos Agregados e Concretos Reciclados. Dissertação (Mestrado) - Escola de Engenharia de São Carlos. Universidade de São Paulo, São Carlos. 2003.

[30] CABRAL, A.E.B.; SCHALCH, V.; DAL MOLIN D.C.C.; el al., Modelagem da retração por secagem de concretos produzidos com agregados reciclados. Revista IBRACON de estruturas e Materias, v.3, pp.123,2010 .

[31] CABRAL, A.E.B. Modelagem de propriedades mecânicas e de durabilidade de concretos produzidos com agregados reciclados, considerando-se a variabilidade da composição do RCD. Tese (Doutorado) - Escola de Engenharia de São Carlos. Universidade de São Paulo, São Carlos. 2007.

[32] ASSOCIAÇÃO BRASILEIRA DE NORMAS TÉCNICAS - ABNT. NBR 5739: 2018. Concreto - Ensaio de compressão com corpos de provas cilíndricos. Rio de Janeiro, 2018.

[33] ASSOCIAÇÃO BRASILEIRA DE NORMAS TÉCNICAS - ABNT. NBR 248: 2003. Agregados - Determinação da composição granulométrica. Rio de Janeiro, 2003.

[34] ASSOCIAÇÃO BRASILEIRA DE NORMAS TÉCNICAS - ABNT. NBR NM 53: Agregado graúdo: determinação da massa específica, massa específica aparente e absorção de água. Rio de Janeiro, 2009.

[35] ASSOCIAÇÃO BRASILEIRA DE NORMAS TÉCNICAS - ABNT. NBR 45: 2006. Agregados - Determinação da massa unitária e do volume de vazios. Rio de Janeiro, 2006.

[36] ASSOCIAÇÃO BRASILEIRA DE NORMAS TÉCNICAS - ABNT. NBR 52: 2009. Agregado miúdo Determinação da massa específica e massa específica aparente. Rio de Janeiro, 2009.

[37] JORDANI, B. Estudo do agregado graúdo reciclado de concreto como agente de cura interna em concreto com cinza de casca de arroz. São Leopoldo, 2016. 104f. Dissertação (Mestrado em Engenharia Civil) Programa de Pós-graduação em Engenharia Civil, Unisinos, São Leopoldo, 2016.

[38] ASSOCIAÇÃO BRASILEIRA DE NORMAS TÉCNICAS - ABNT. NBR 5738: 2015. Concreto - Procedimento para moldagem e cura de corpos de prova. Rio de Janeiro, 2015.

[39] RIBEIRO, G. D.; GOMES, M. V.; VALIN JR, M. O. Influência da cura do concreto com e sem a utilização de lona plástica na resistência mecânica e absorção de água. In: $56^{\circ}$ CONGRESSO BRASILEIRO DO CONCRETO/IBRACON, 2014. Natal. Disponível em: <http://www.mvalin.com.br/products/influ\%C3\%AAncia-dos-procedimentos-de-cura-naresist\%C3\%AAncia-e-absor\%C3\%A7\%C3\%A3o-do-concreto/>. Acesso em: 17 abril 2019.

[40] VALIN JR, M. O.; LIMA, S. M. Influência dos procedimentos de cura na resistência e absorção do concreto. In: $51^{\circ}$ CONGRESSO BRASILEIRO DO CONCRETO/ IBRACON, 2009. Curitiba. Disponível em:< http://www.mvalin.com.br/ products/influ \%C3\%AAncia-dos-procedimentos-de-cura-naresist\%C3\%AAncia-e-absor\%C3\% A7\%C3\%A3o-do-concreto/>. Acesso em: 17 abril de 2019.

[41] PAULON, V.A. A microestrutura do concreto convencional. CONCRETO, Ensino, Pesquisa e Realizações. Ed. G.G. Isaia. São Paulo: IBRACON, v. 2, p. 1600, 2005.

[42] BUTTLER, A.M. Uso de Agregados Reciclados de Concreto em Blocos de Alvenaria Estrutural. Tese (Doutorado) - Escola de Engenharia de São Carlos. Universidade de São Paulo, São Carlos. 2007.

[43] LEITE, M.B. Avaliação de propriedades mecânicas de concretos produzidos com agregados reciclados de resíduo de construção e demolição. Tese (Doutorado). UFRGS, 2001.

[44] VARGAS, P.; RESTREPO-BAENA, O.; TOBÓN, J. I. Microstructural analysis of interfacial transition zone (ITZ) and its impact on the compressive strength of lightweight concretes. Construction and Building Materials, v. 137, n. 15, pp. 381-389, 2017.

[45] DUAN, Z. H.; POON, C. S. Properties of recycled aggregate concrete made with recycled aggregates with different amounts of old adhered mortars. Materials and Design, v. 58, pp. 19-29, 2014.

[46] KOU, S. C.; POON, C. S. Mechanical properties of 5-year-old concrete prepared with recycled aggregates obtained from three different sources. Magazine of Concrete Research, v. 60, n.1, pp. 57-64, 2008.

\section{ORCID}

Beatriz Cordeiro de Souza Cássia Nayara dos Santos Paes Lucas da Silva Barboza https://orcid.org/0000-0001-9144-3082 https://orcid.org/0000-0003-3530-2028 http://orcid.org/0000-0003-0027-9104 